DE-FC36-07G017044

Concentrating Solar Panels

Soliant Energy, Inc.

\title{
Technology Pathway Partnership Final Technical Report
}

Project Title:

Reporting Period:

Date Submitted:

Recipient:

Award Number:

Recipient Contacts:

DOE Project Team:
Concentrating Solar Panels

September 3, 2007 to August 31, 2010

January 5, 2010

Soliant Energy, Inc. f/k/a Practical Instruments

DE-FC36-07G017044

Michael Deck

Phone: 626-239-3433

Fax: 626-628-3660

Email: michael.deck@soliantenergy.com

$\begin{array}{lll}\text { DOE Field Contracting Officer } & - & \text { Andrea Lucero } \\ \text { DOE Field Project Officer } & - & \text { Leon Fabick } \\ \text { Project Engineer } & - & \text { Sven Nuesken } \\ \text { Technical Monitor } & - & \text { Nathan Siegel }\end{array}$

\section{Acknowledgement}

This material is based upon work supported by the Department of Energy, Office of Energy of Efficiency and Renewable Energy under Award Number DE-FC36-07G017044.

\section{Disclaimer}

This report was prepared as an account of work sponsored by an agency of the United States Government. Neither the United States Government nor any agency thereof, nor any of their employees, makes any warranty, express or implied, or assumes any legal liability or responsibility for the accuracy, completeness, or usefulness of any information, apparatus, product, or process disclosed, or represents that its use would not infringe privately owned rights. Reference herein to any specific commercial product, process, or services by trade name, trademark, manufacturer, or otherwise does not necessarily constitute or imply its endorsement, recommendation, or favoring by the United States Government or any agency thereof. The views and opinions of authors expressed herein do not necessarily state or reflect those of the United States Government or any agency thereof.

\section{Distribution}

This report is acceptable for distribution.

\section{Executive Summary}

Soliant Energy is a venture-capital-backed startup focused on bringing advanced concentrating solar panels to market. Our fundamental innovation is that we are the first company to develop a racking solar concentrator specifically for commercial rooftop applications, resulting in the lowest LCOE for rooftop electricity generation.

Today, the commercial rooftop segment is the largest and fastest-growing market in the solar industry. Our concentrating panels can make a major contribution to the SAl's objectives: reducing the cost of solar electricity and rapidly deploying capacity. 
Our commercialization focus was re-shaped in 2009, shifting from an emphasis solely on panel efficiency to LCOE. Since the inception of the SAI program, LCOE has become the de facto standard for comparing commercial photovoltaic systems. While estimation and prediction models still differ, the emergence of performance-based incentive (PBI) and feed-in tariff (FIT) systems, as well as power purchase agreement (PPA) financing structures make LCOE the natural metric for photovoltaic systems.

Soliant Energy has designed and demonstrated lower-cost, higher-power solar panels that consists of 6 (500X) PV module assemblies utilizing multi-junction cells and an integrated two-axis tracker. In addition, we have designed and demonstrated a prototype 1000X panel assembly with 8 . Cost reductions relative to conventional flat panel PV systems were realized by 1) reducing the amount of costly semiconductor material and 2) developing strategies and processes to reduce the manufacturing costs of the entire system. Performance gains against conventional benchmarks were realized with 1) two-axis tracking and 2) higher-efficiency multi-junction PV cells capable of operating at a solar concentration ratio of $1000 \mathrm{X}$ (1000 kW/m2).

\section{Program Objectives and Accomplishments}

Objectives:

- Develop a tracking/concentrating solar module that has the same geometric form factor as a conventional flat, roof mounted photovoltaic (PV) panel. The Soliant module will produce more power and cost less than conventional panels of the same size.

- Target LCOE: \$0.079/kWh in 2010

- Target efficiency: $26 \%$ in 2010 (22\% for 2008 prototype, $24 \%$ for 2009 pilot)

- Target performance: equivalent to 650Wp in 2010 (490W for 2008 prototype, 540W for 2009 pilot)

Accomplishments:

2008

- Delivered prototype tracking/concentrating solar module that mounts to standard racking systems on commercial rooftops, with standard output electrical connections.

- Prototype unit equivalent to $414 \mathrm{~W}$ per Sandia evaluation

- Prototype unit $23 \%$ collector efficiency, $17.6 \%$ total area efficiency

- Build-up pilot manufacturing line to deliver pilot units October 2008.

2009

- Designed and built pilot plant capable of producing over 1MWp1 per year of manufactured tracking/concentrating solar panels that mount to standard racking systems on commercial rooftops, with standard output electrical connections.

- Expanded earlier system on Soliant HQ rooftop to full $4.4 \mathrm{kWp}$; system operated within specifications for most of 2009 until decommissioned for research purposes

- Installed two $2.0 \mathrm{kWp}$ beta systems on customer rooftops.

- Internally tested units with energy output equivalent to $449 \mathrm{Wp}$ flat plate

2010

- Produced over 274 SE-500Xb panels

- Installed additional 40kWp on customer rooftops.

- Resolved an issue (previously identified as "cell failure") that was due to variations in thermal bonding

- Built and proved feasibility of $1000 x$ module and 8-module panel; investigated causes and potential solutions to premature failure issues; improved ability to predict panel performance and measure actual against predictions

- Received UL listing of SE-500X panel against SU 8703 draft safety standard.

\footnotetext{
${ }^{1}$ Beginning in Phase 2 of the project, Soliant discontinued use of the descriptive but non-standard "watts equivalent" in favor of the emerging CPV Wp STC standard that is emerging from IEC TC82 WG7. In this report the phrase "equivalent to Wp" is used where necessary to maintain a link to the original proposal, in all other places Wp means CPV Wp STC.
} 
- Identified failure mechanism causing premature failures at beta sites; continued to improve prediction and monitoring capability; started side by side soiling study.

- Opened preliminary investigation with UL for re-certification of SE-1000X panel against SU 8703

\section{Summary of Project Activities}

Soliant Energy was a venture-capital-backed startup focused on bringing advanced concentrating solar panels to market. Our fundamental innovation was that we were the first company to develop a racking solar concentrator specifically for commercial rooftop applications, resulting in the lowest LCOE for rooftop electricity generation.

Today, the commercial rooftop segment is the largest and fastest-growing market in the solar industry. Our concentrating panels can make a major contribution to the SAl's objectives: reducing the cost of solar electricity and rapidly deploying capacity.

Our commercialization focus was re-shaped in 2009, shifting from an emphasis solely on panel efficiency to LCOE. Since the inception of the SAI program, LCOE has become the de facto standard for comparing commercial photovoltaic systems. While estimation and prediction models still differ, the emergence of performance-based incentive (PBI) and feed-in tariff (FIT) systems, as well as power purchase agreement (PPA) financing structures make LCOE the natural metric for photovoltaic systems.

During this program, Soliant made progress on several fronts including manufacturing capacity, technology development, market awareness, and sales.

Because the Soliant effort was intended to produce capital equipment with high reliability under harsh conditions, our technical approach was borrowed from the automotive industry. The first phase of our effort, from 9/07 through 3/08, was Engineering Validation (EV) with a goal of demonstrating a working product design. We completed this phase with delivery of our prototype unit validated by Sandia to meet all key objectives.

The second phase was Design Validation (DV) which further refined the design and readied it for manufacturing. We made substantial progress toward completing this phase by establishing a pilot manufacturing line at our facility in Monrovia, CA. This phase was to be completed in December 2008. However, product improvements identified during the initial part of the DV prompted Soliant to undertake a second DV iteration.

The third phase was Production Validation (PV) and culminated in the first large-scale deliveries of our product to customers in 2010.

The technical approach of the original proposal included a strong but largely separate task of receiver packaging development. Although we continued to report on this task for DOE purposes, organizationally it was tightly coupled into our overall product development effort.

The major focus of our effort in FY2008 was to specify our market entry concentrating solar panel, produce a working prototype for Sandia's test and evaluation, and make progress on completing our manufacturing pilot plant. With a few modifications, we accomplished these goals. We specified, designed, produced, and validated concentrating solar panel that produces annual power equivalent to $414 \mathrm{Wp}$ flat plate. The panel had a $23 \%$ collector efficiency and a $17.3 \%$ total area efficiency. These results are slightly poorer than outlined in the negotiated project objectives but the reasons are understood. In addition, detailed models produced during this FY suggest that space/power tradeoffs in the current module design may result in a lower LCOE and higher return on investment than originally expected, because of improvements in shade tolerance and spacing parameters. Figure 1 shows the original prototype (EV) panel on site at Sandia.

Following delivery of the prototype panel in March 2008, we began work on building our pilot manufacturing line. The tooling was kicked off and contracts for long lead time equipment let in April 2008. In July 2008 we moved from our cramped Pasadena, CA facility to a larger building 6 miles away in 
DE-FC36-07G017044

Concentrating Solar Panels

Soliant Energy, Inc.

Monrovia, CA. At the end of the FY, we had received all of the machinery for the pilot line and were tuning and debugging it.

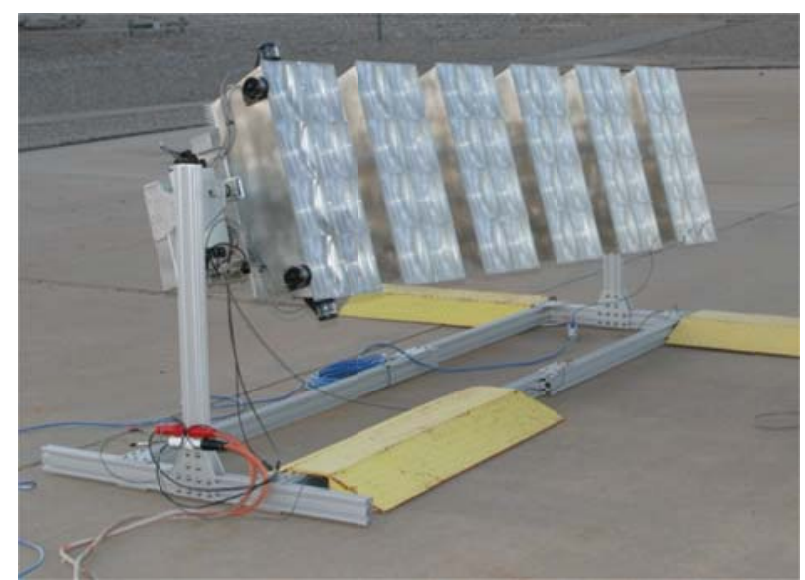

Figure 1. Soliant Prototype Panel at Sandia

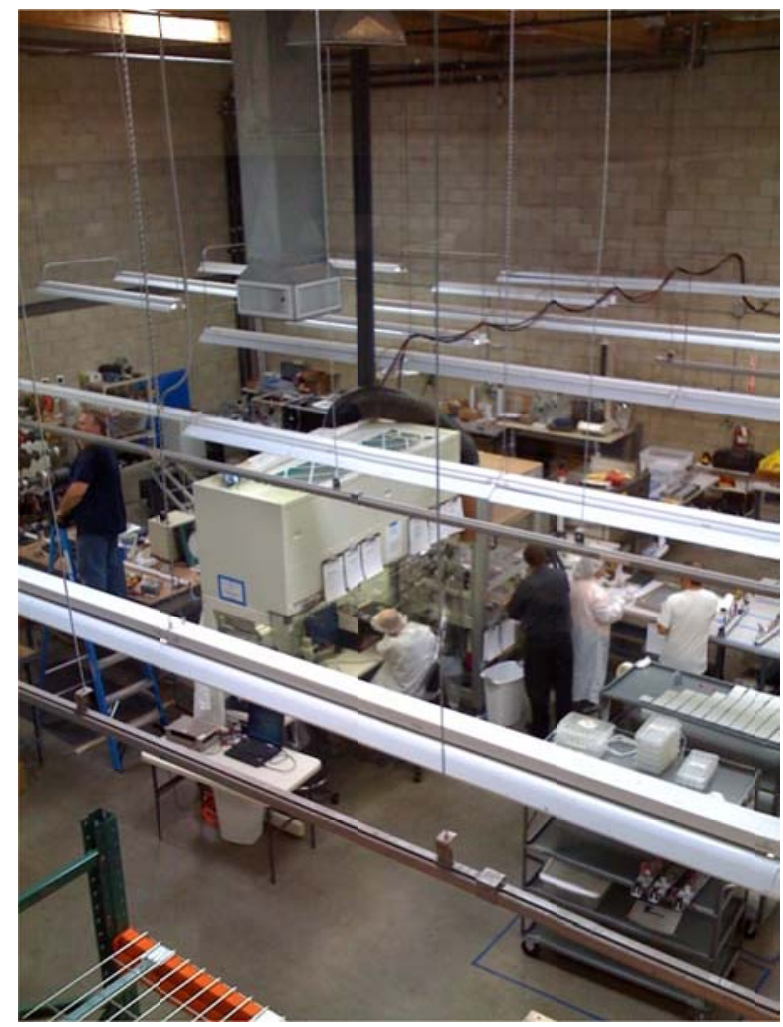

Figure 2. Soliant Pilot Manufacturing Facility

Also in our facility, we developed an in-house testing capability that allowed us to do a variety of environmental tests on panel components, paving the way for UL listing in 2010. A photograph of our reliability lab is shown below. 
DE-FC36-07G017044

Concentrating Solar Panels

Soliant Energy, Inc.

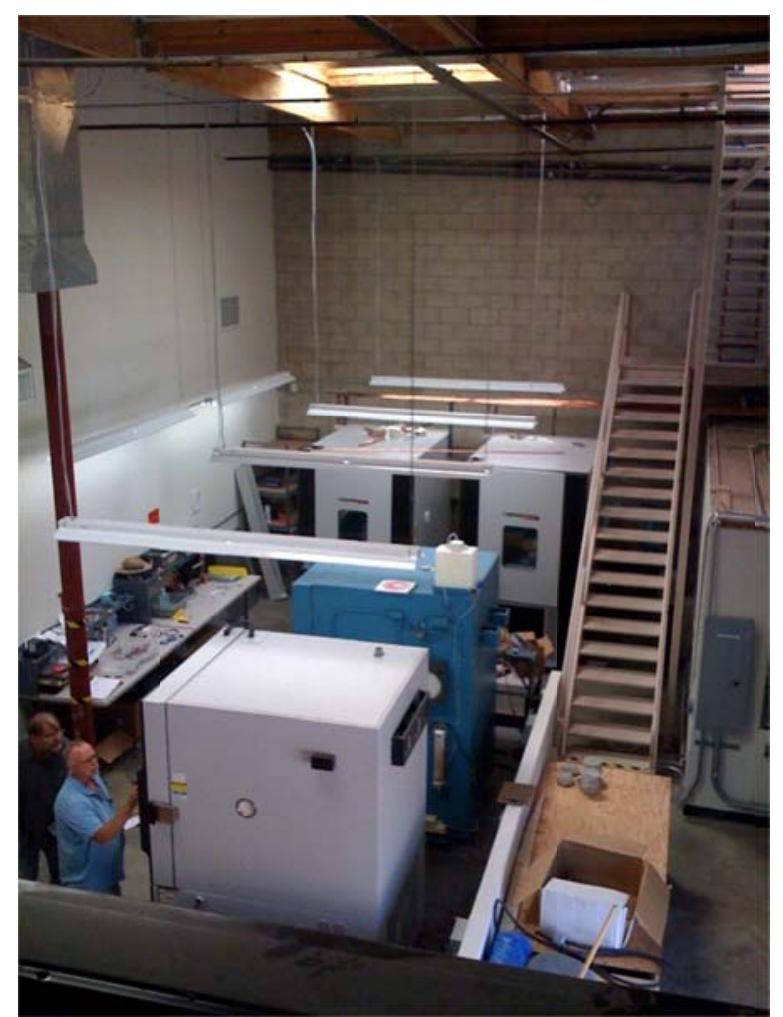

Figure 3. Soliant Reliability Lab

Planned activities for Soliant also included developing a receiver packaging capability as a separate task. We have developed this capability and reported on it to Sandia.

Two subcontract research initiatives were kicked off with MIT. One of these, under the direction of Prof. Jung-Hoon Chun, is studying the manufacturing impacts of various alternatives in a multi-echelon supply chain. The other, directed by Prof. Martin Culpepper, is investigating mechanisms for three-dimensional articulation of our optical element.

The major focus of our effort in 2009 was to ramp up manufacturing capacity of a panel that would pass UL and meet customer needs. With a few modifications, we accomplished this goal. We specified, designed, equipped, and validated a pilot-scale manufacturing plant that, running at full capacity, could produce in excess of $600 \mathrm{kWp}$ of Soliant SE-500X concentrating solar panels. The Soliant SE-500X produces an annual power equivalent to $449 \mathrm{Wp}$ flat plate, or $416 \mathrm{kWh} / \mathrm{m}^{2} / \mathrm{yr}$ in Phoenix. The energy output of the beta SE-500X was measured by Sandia in early 2009 using panels produced to the same specification in 2008. Figure shows the Soliant rooftop array making full power from the early morning sun. 
DE-FC36-07G017044

Concentrating Solar Panels

Soliant Energy, Inc.

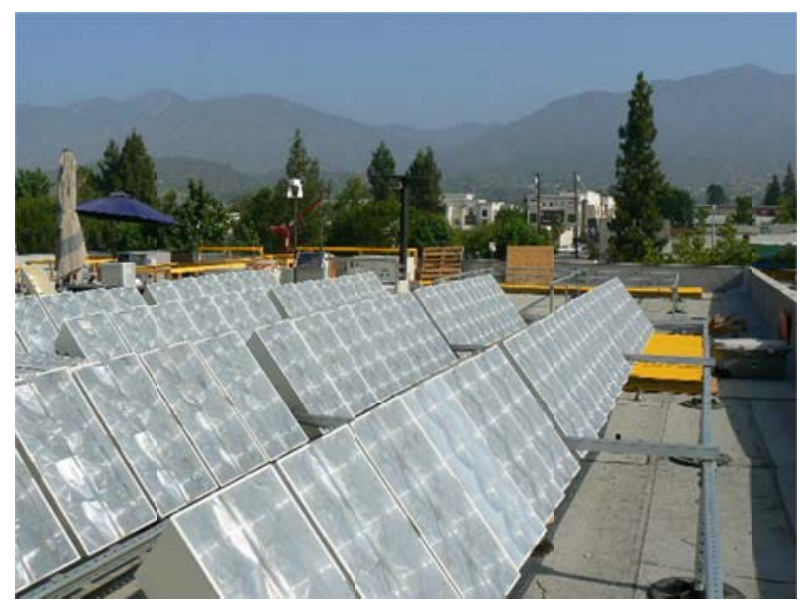

Figure 4. The 4.4kWp Array at Soliant HQ

In April we leased an additional building adjacent to our Monrovia headquarters and outfitted it as our module- and panel-assembly line. The ribbon-cutting for this facility took place in August and first panels were delivered from it in September. Congressman David Dreier is $3^{\text {rd }}$ from right in Figure 5.

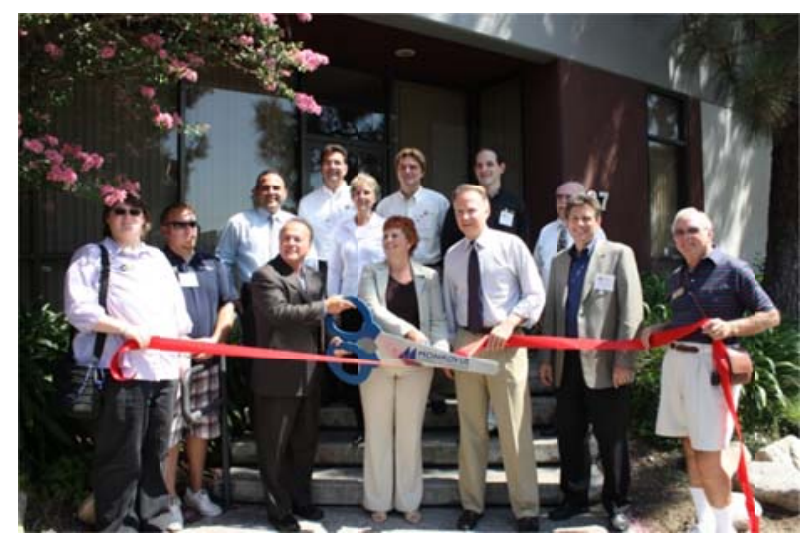

Figure 5. Ribbon-Cutting for Pilot Plant

Important progress was made in 2009 toward UL listing of our SE-500X product. Soliant worked closely with UL to define the UL8703 draft safety standard for photovoltaic concentrators. Soliant passed the fire testing elements of this standard in 2009 and at year end was accumulating hours toward the long-term tests such as outdoor exposure.

Our subcontract with MIT saw further progress. Under the direction of Prof. Jung-Hoon Chun, a student had been developing a model for impacts of various alternatives in a multi-echelon supply chain. Another student, directed by Prof. Martin Culpepper, was investigating mechanisms for three-dimensional articulation of our optical element. 
DE-FC36-07G017044

Concentrating Solar Panels

Soliant Energy, Inc.

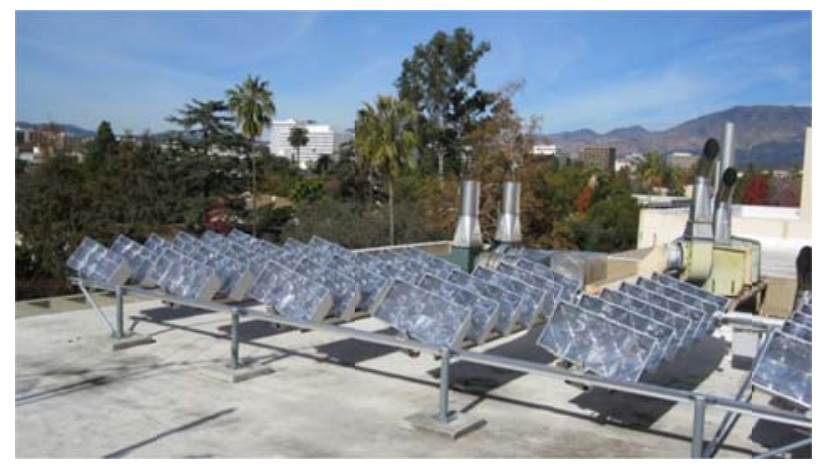

Figure 6. Beta System Installed

In December 2009, we delivered two beta systems of approximately $2 \mathrm{kWp}$ each to $3^{\text {rd }}$ party evaluators. One of these systems, shown above in Figure 6, was immediately grid-connected; the other was gridconnected in 1Q10.

Between 1Q10 and 3Q10 we produced over 274 SE-500Xb panels. A total of 40kWp of these were installed on customer rooftops in the US, Europe and North Africa. During the course of this production we resolved a failure mode causing our receivers to go into thermal runaway that was due to variations in thermal bonding between the receiver package and the heat sink.

As part of our research and development efforts towards a next generation product, we built and proved feasibility of a 1000x module and an 8-module panel and were able to combine these two advances into a prototype of the SE-1000X panel. We investigated and determined root cause of a premature failure issue that resulted in the degradation of the cell metallization. We worked with our suppliers to find alternate production materials and processes that would avoid this failure.

After installation of $40 \mathrm{kWp}$ of panels at various sites and the installations on Soliant's rooftop in Monrovia, significant effort was spent to improve our ability to predict panel performance and measure actual energy generation against predictions. Almost immediately after receiving our UL listing of SE500X panel against SU 8703 draft safety standard, we opened a preliminary investigation with UL for recertification of SE-1000X panel against SU 8703.

\section{Patents and Publications}

4 US patent applications were submitted during this program and 1 was issued.

"Soliant Energy Concentrator Module Performance And Comparison To Silicon Flat Panel Performance" by Neil Fromer, Richard Johnson, Simone Missirian and Jason Bobruk (all Soliant employees) was presented in a poster session at the $34^{\text {th }}$ Annual IEEE Photovoltaic Specialists' Conference (PVSC34). A similar paper was presented in a poster session at the SPIE Solar Energy + Technology 2009 conference held in San Diego, August 2009. 